\title{
Severe magnetic storm effects in the ionosphere over Istanbul: a case study
}

\author{
Harutyun Agopyan \\ Istanbul University, Vocational School of High Technology, Istanbul, Turkey
}

\begin{abstract}
The present study concentrates on the effects on the ionosphere of an individual severe magnetic Storm of the Sudden Commencement (SSC) type, with SSC taking place in the daytime hours. The storm started on 29 October 1968 and went on to 2 November 1968 with geomagnetic 3-hourly magnetic activity index reaching values of $K_{p} \geq 7$. Interplanetary magnetic field polarities included $A$ (field polarity Away from the solar wind) positive and $T$ (field polarity Towards the solar wind) negative polarities. In these conditions, the local response of true height of $F$ region $(h F)$ ionization fails nonlinearly from fixed plasma densities. The interplanetary $B_{z}$, the magnetic field $H$ component and $K_{p}$ were examined for the 5 days following the sudden commencement. Due to intensive geomagnetic SC effects, the lower and upper limits of the $F$-regions were unbalanced because of gravity relaxation and solar wind pressure effects, until normal levels were restored. In the $F$-layer $70 \%$ deviations of critical frequencies $\left(f_{0} F\right)$ from median values, as well as $h F$ level variations reaching hundreds of kilometers, were observed and were responsible for the destruction of communication channels. With a plasmapause location value $L=1.6$ and with $K_{p} \geq 7$ the protonosphere reservoir should take 1.1 days for its replenishment; one day was in fact insufficient for a full plasma recovery.
\end{abstract}

Key words geomagnetic activity - ionospheric positive storm - neutral gas concentration excess radio reception - ring current

\section{Introduction}

A Geomagnetic Storm (GS) is the result of strong enhancement of Ring Currents (RC) in which the Earth's Magnetic Field (EMF) is usually depressed below its normal quiet day value. An Ionospheric Storm (IS) is the ionospheric effect of a GS that increases or decreases the electron density $\left(N_{e}\right)$ and the Total Electron Content $\left(N_{\text {TEC }}\right)$ of the $F$-region; please refer to Förster and Jakowski (2000) and references therein, for a review on these phenomena. There are two kinds of ISs known as negative ISs and

Mailing address: Associate Prof. Dr. Harutyun Agopyan, Istanbul University, Vocational School of High Technology, 34320, Avcilar, Istanbul, Turkey. Former address: I.C.T.P., 34100 Trieste, Italy. e-mail: harutyun@ istanbul.edu.tr positive ISs, depending on the Local Time (LT) of onset of GS, latitude and season. The response of critical frequency of the $F$-region $\left(f_{0} F_{2}\right)$ depends markedly on season and solar and geomagnetic activity, and also on geomagnetic latitudes (Matsushita, 1959). Most of the winter storms show enhancements, whereas summer storms and equinox storms show depressions following short-lived enhancements. The Interplanetary Magnetic Field (IMF) during spring has an $A$ (field polarity Away from the solar wind), anti-sunward polarity, inducing $+B_{z}$ values, and $T$ (field polarity Toward the solar wind) during autumn it has a sunward polarity, inducing $-B_{z}$ values. Thus, inverse $B_{z}$ signs are most common for October storms. Solar flare-induced storms are weak but last a few days longer, because of the time taken for the stream to pass over the Earth. Several years ago, Dungey (1961) and Akasofu and Chapman (1963) claimed that the energy transfer mechanism from the solar wind to the magnetosphere is a magnetic reconnection between the southward IMF $-B_{z}$ and the Earth's 
dipole EMF. The non-linearity of the magnetosphere and ionosphere both depend on the $\mathrm{RC}$ energy injection rate (Akasofu, 1981). Mendillo and Klobuchar (1975) presented TEC storm behavior after the important discovery of a trough producing a negative phase that begins progressively later at sites with lower latitudes. Prölss (1987) investigated the temperature response of the upper thermosphere, and gave quantitative results on composition changes. He also published a thermospheric model but suggested that further studies are required for negative ISs at middle latitudes. Models differ significantly near $200 \mathrm{~km}$ where the nitrogen $\left(\mathrm{N}_{2}\right)$ density is important and oxygen $(\mathrm{O})$ is depleted in the summer. Prediction of atomic $\mathrm{O}$ density in new solar cycles will require new satellite missions and revival satellite drag analyses, or improved methods of monitoring from the ground (Hedin, 1988). Rees et al. (1988) found that, at fixed pressure levels, the increase in mean molecular weight spread only a short distance from the auroral oval can be taken as evidence that negative ISs at lower latitudes cannot be due to changes in the neutral gas composition. The $\mathrm{N}_{2} / \mathrm{O}$ density ratio is important together with that of other minor constituents assuming that the pressure scale height is approximately constant above $280 \mathrm{~km}$. Hewish and Duffet-Smith (1987) suggested a means of giving warning of impending high speed solar wind streams at $1 \mathrm{AU}$. This would allow predictions of time intervals where there will be higher probabilities of MS occurrence (Tsurtani et al., 1988).

The present study aims to contribute to satellite communications and as well as to ionospheric model studies for especially high geomagnetic activity conditions.

\section{Observation}

Observations of the hourly behaviour of the critical frequency of the $F_{2}$ layer of the ionosphere have been analyzed for their percentage deviations from their monthly median values

$$
\Delta f_{0} F_{2}=\frac{\left(f_{0} F_{2}\right)_{\text {hourly }}-\left(f_{0} F_{2}\right)_{\text {median }}}{\left(f_{0} F_{2}\right)_{\text {median }}} \times 100 .
$$

The above measure of $\Delta f_{0} F_{2}$, peak height values of $h_{p} F_{2}$,minimum height values of $h_{\min } F$ and virtual height values of $h^{\prime} F$ for Istanbul (geographic coordinates $41^{\circ} \mathrm{N} ; 29^{\circ} \mathrm{E}$; geomagnetic coordinates $39^{\circ} \mathrm{N}$; $108^{\circ} \mathrm{E}$; Mc Ilwain (1961) Earth's magnetic shell parameter $L \cong 1$.6) have been analyzed to reveal the behavior of the ionosphere during strong GS disturbances. Observations were made during the high solar activity period from 29 October 1968 to 2 November 1968. During this interval, $\mathrm{D}(\gamma) \geq 120$ and quite high magnetic activity indices of $K_{p} \geq$ 7 were observed extensively (Uyar, 1964; Bulat and Agopyan, 1980; Agopyan, 1986, 1988 and 1996).

Figure 1a shows the percentage deviation of $f_{0} F_{2}(\mathrm{MHz})$ during the severe Magnetic Storm (MS) period of 5 days. It is seen that the $f_{0} F_{2}$ values always show clear increases from the monthly medians of about $50 \%$ to $70 \% 8$ or $10 \mathrm{~h}$ after the beginning of a SSC. However, the wireless Short Wave (SW) prediction $10 \mathrm{MHz}$ for $f_{0} F_{2}$ goes to $17 \mathrm{MHz}$ during a severe GS. So it is advisable to tune to the higher frequencies. In other words, it would be better to lower the wavelength for SW radio reception (i.e. instead of noisy reception on the $31 \mathrm{~m}$ band, it would be better to tune to the $19 \mathrm{~m}$ band). In fig. $1 \mathrm{~b}$, hourly values of $h_{p} F_{2}$ and $h_{\min } F$ are plotted. This shows the ionospheric plasma situation more clearly during a strong GS series (29/30/31 October $1 / 2$ November 1968). During the first day of the storm, the height changes are over $250 \mathrm{~km}$. It can be seen that no changes in height occur during the sunlit hours but they are significant during night hours. Nocturnal $h_{p} F_{2}$ and $h_{\min } F$ crossing on November 1 electric current increases and cross generations of EMF present ionospheric $\mathrm{G}$ condition existence respectively (Agopyan, 1988).

In fig. 2, maximum electron density $\left(N_{\mathrm{m}} F_{2}\right.$. $\left.10^{5} \mathrm{e} \mathrm{cm}^{-3}\right)$, frequency $\left(f_{0} F_{2} \cdot 1 \mathrm{MHz}\right)$, monthly median $\left(N_{\mathrm{MED}} F_{2} \cdot 10^{5} \mathrm{e} \mathrm{cm}^{-3}\right)$ and $K_{p}$ ranges are plotted against time for 28 October 1968 from $00 \mathrm{~h} 00 \mathrm{LT}$ to $24 \mathrm{~h} 00 \mathrm{LT}$. The following days containing missing values have been omitted. The electron-density versus time curves are not suitable for studying the electron concentration changes at various heights because of strong day/ night differences during the storm. Therefore 

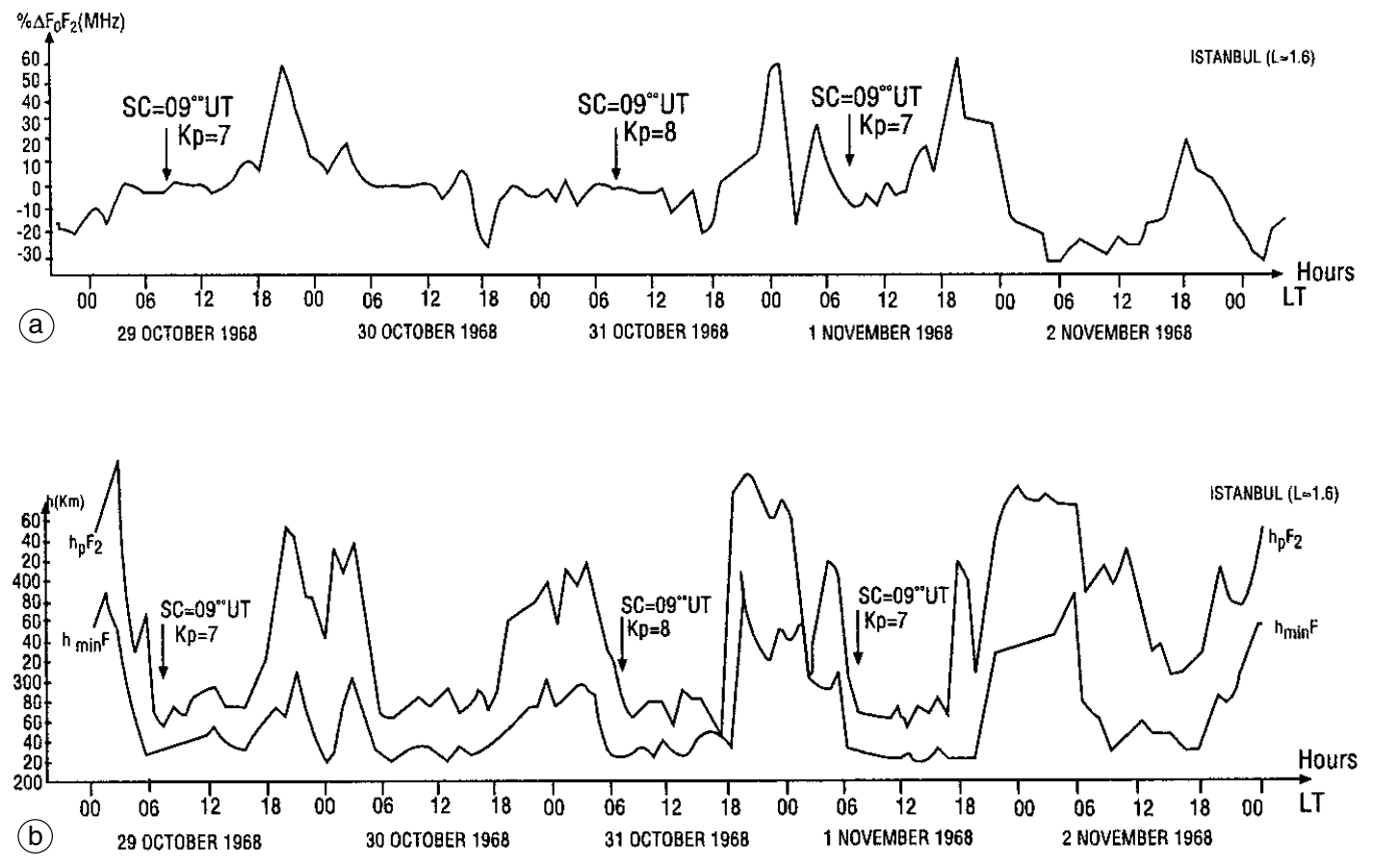

Fig. 1 a,b. a) Percentage critical frequency deviations from monthly medians $\left[\Delta f_{0} F_{2}(\mathrm{MHz})\right]$ versus consecutive local time $(\mathrm{LT}=\mathrm{UT}+2)$ hours with storm sudden commencement $(\mathrm{SSC})$ occurrences for 29 October to 2 November 1968; b) minimum to maximum height variation of the ionospheric $F$-layer versus local time (LT) hours.

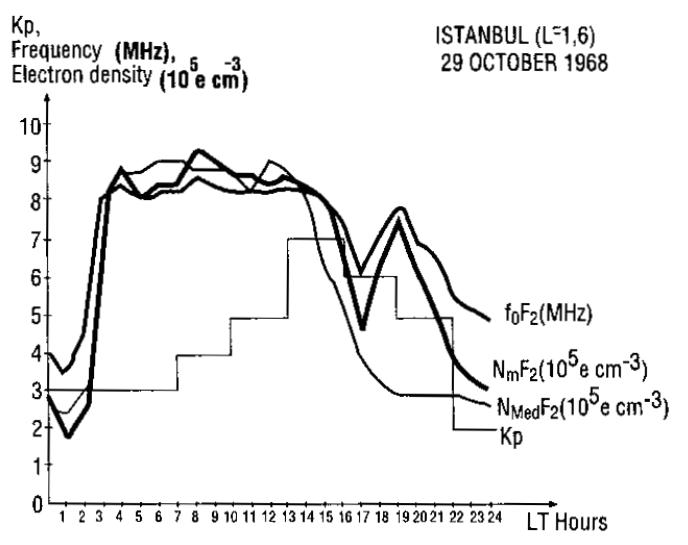

Fig. 2. Electron density $\left(10^{5} \mathrm{e} \mathrm{cm}^{-3}\right), N_{\text {med }} F_{2}\left(10^{5} \mathrm{e}\right.$ $\mathrm{cm}^{-3}$ ), frequency (Mhz), and $K_{p}$ ranges versus local time for 29 October 1968 between $00 \mathrm{~h} 00 \mathrm{LT}$ to $24 \mathrm{~h}$ 00 LT hours. fig. 3 shows isoionic contour plots of electron densities derived from true height profiles. Here fixed plasma density variations show a decreasing amplitude of plasma wavelike behaviour as isoionic counter plots for the storm that started on 29 October, 1968 and continued for 5 days. The increase in height for various electron density values during the night and their nonlinear behaviour are not only the result of Coronal Mass Ejections (CME) of the Sun but also partly due to the effects of tides, wind pressures and gravity relaxation occurred progressively. From the fig. 3 , most of the height changes of density values in between $1.5-6.5 \cdot 10^{5} \mathrm{e} / \mathrm{cm}^{3}$ occur near $20 \mathrm{~h} 00 \mathrm{LT}$. The variation is from $500 \mathrm{~km}$ to nearly $700 \mathrm{~km}$ at the topside window of the ionosphere (Agopyan, 1988). Here, the electron concentration of $\mathrm{O}^{+}$ions is too low for a reliable 


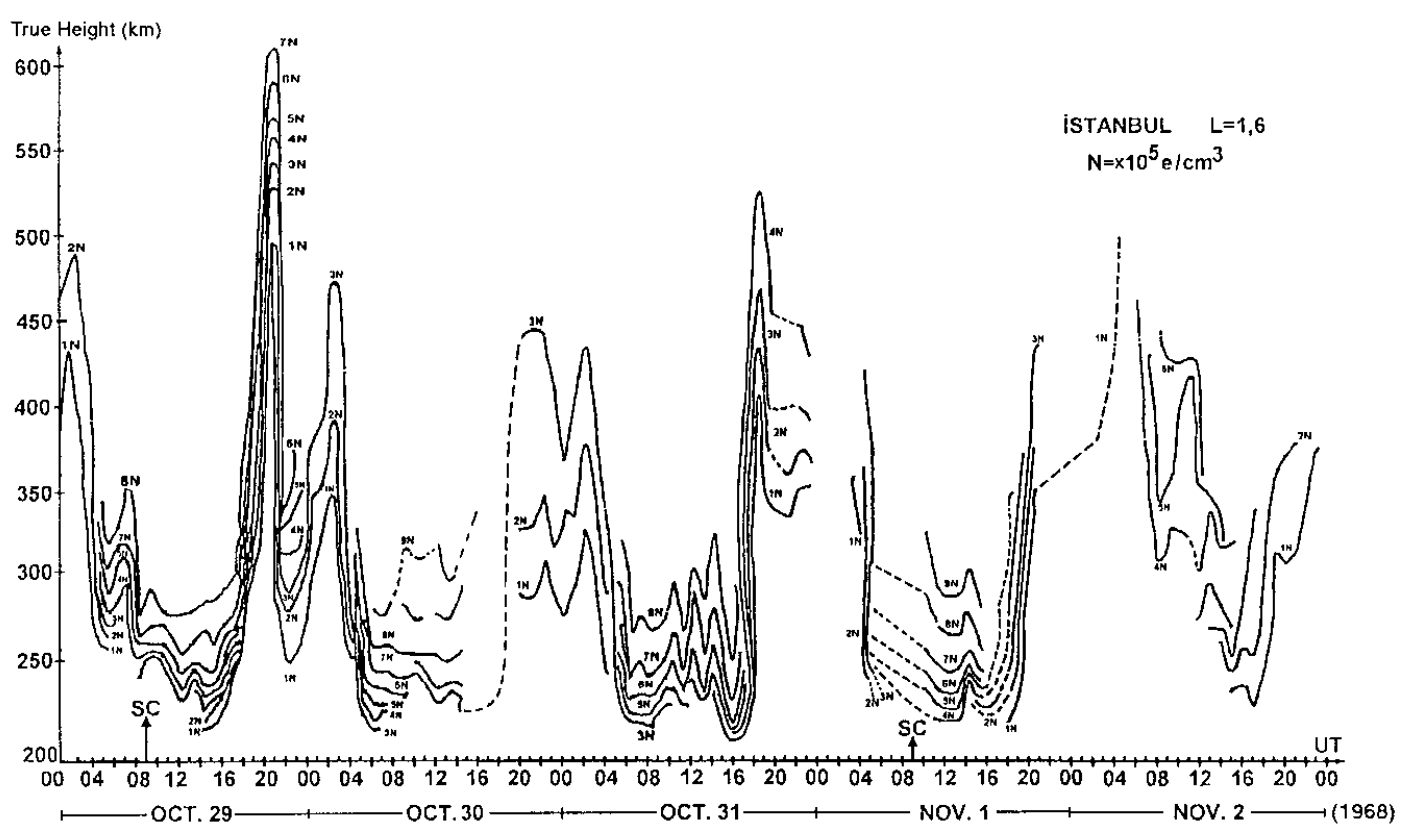

Fig. 3. Isoionic contours derived from $N(h)$ analysis of ionograms for between 29 October to 2 November 1968 show true height variations $h(\mathrm{~km})$ of whole storm series throughout the $5 K_{p} \geq 7$ days showing disturbed wavelike behaviour of plasma densities.

determination of the height. The most convenient time of day seems to be in the evening at $17 \mathrm{~h} 00$ LT, when height variations of no more than 50 $\mathrm{km}$ are seen (the height remains between 250 and $300 \mathrm{~km})$.

The data have been subjected to spectral analysis. In fig. 4 , the power spectra including Hanning windowing (Claerbout, 1985 and Press et al., 1988) show the effects of planetary waves having about 12 hourly period. Lunar and solar hourly periods with periods around $5 \mathrm{~h}, 18 \mathrm{~h}$, and $64 \mathrm{~h}$. Furthermore, the power spectral density including Hanning windowing shows that the similar results are present during the storm period as is seen in fig. 5. Besides solar tide that can affect the acceleration of gravity over $280 \mathrm{~km}$ where pressure scale height becomes important on $\mathrm{N}_{2} / \mathrm{O}$ density ratio equilibrium not only plasma waves, minor constituents but also lunar and tidal local effects should be taken into consideration for further investigations.
In fig. $6, K, \mathrm{IMF}(\mathrm{Bz})$ and the $H$-component of the magnetic field are plotted for the 5 days of the SC storms (Agopyan, 1986) observed worldwide from 29 October 1968 to 2 November 1968 , including $A$, Antisunward positive and $T$, Toward the Sun negative polarities. If the IMF sector boundary crossings are effective with their $A$ or $T$ polarities, thus the variation of $f_{0} F_{2}$ during $T \rightarrow A$ and $A \rightarrow T$ transitions could be explained by the solar wind speed (fig. 2 and fig. 9; Bremer, 1988). There is a positive correlation between amplitudes and phases of sunspot cycle, $K$-index and EMF, but, particularly in equinoctial months, the first harmonic of the $H$-component varies irregularly with sunspot number. The seasonal variation of amplitudes and solar cycle variation of amplitude harmonics (smoothed) have been investigated for disturbed days together with the yearly variation and sunspot number and $K$-index, and also for the $H$-component (Iş1kara, 1971). The $K$-index since 1952 from the Kandilli 


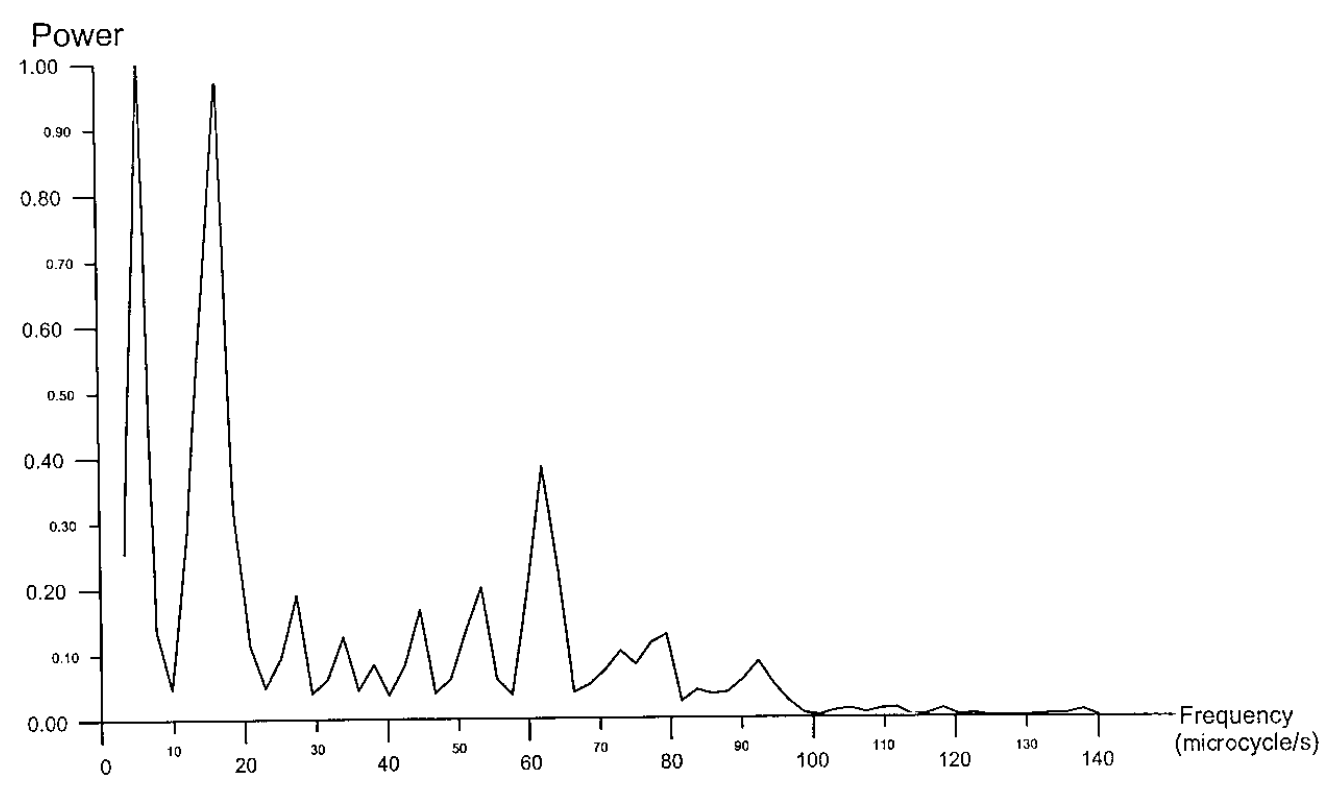

Fig. 4. Power spectra of the electron density value of the ionospheric storm including Hanning windowing.

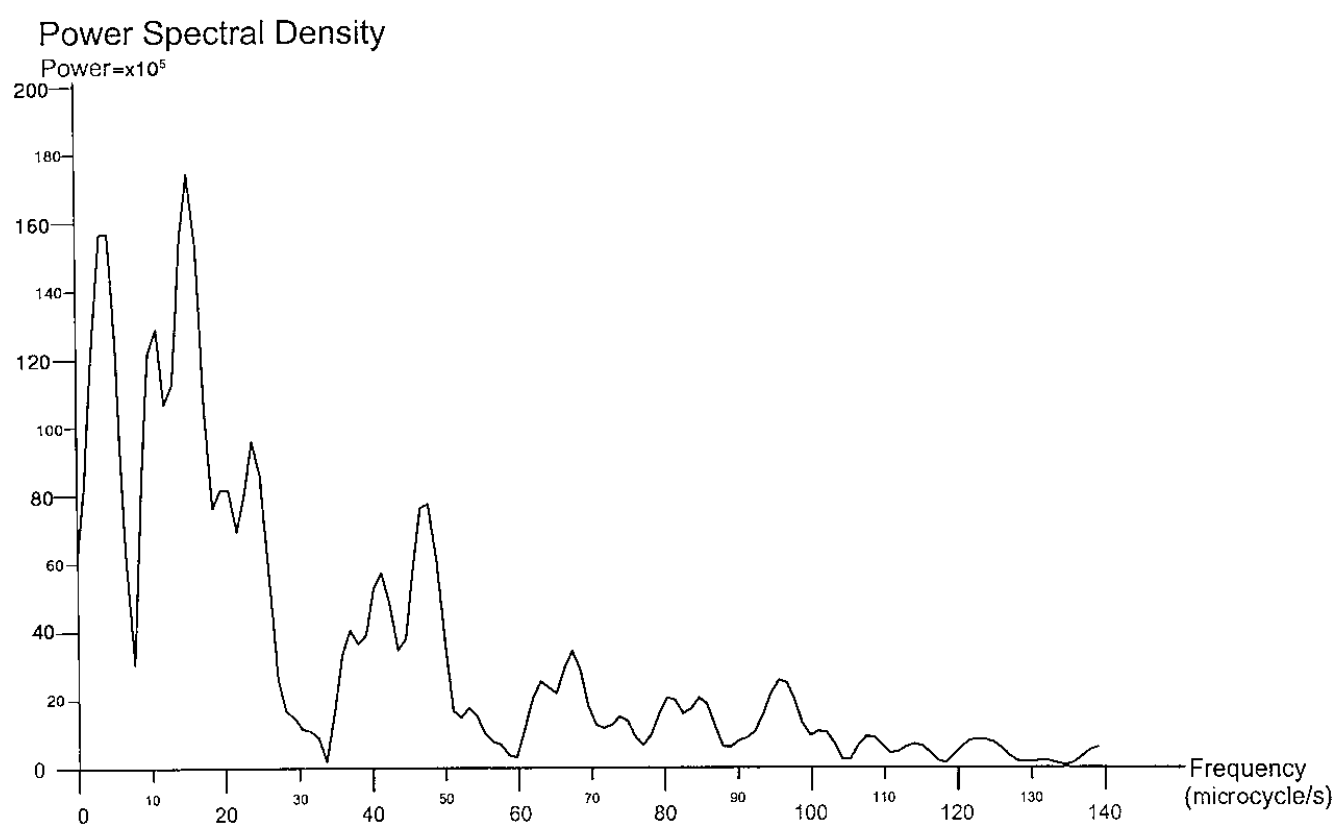

Fig. 5. Power spectral density of the electron density value of the ionospheric storm including Hanning windowing. 


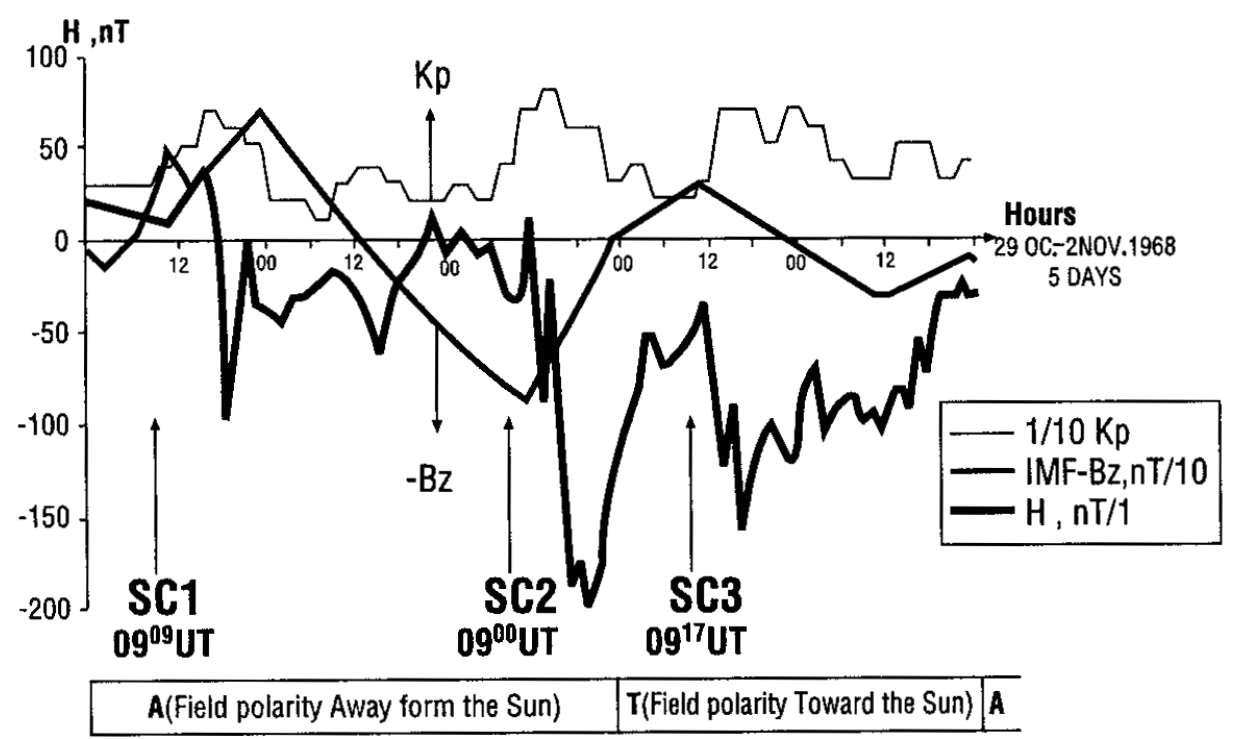

Fig. 6. Comparison of $K_{p}$, IMF $\left(B_{z}\right)$ and $H$-component magnetic field variations for the 5 days of the SC storms observed on 29, 30, 31 October - 1, 2 November 1968, including A (field polarity Away from the solar wind) positive and $T$ (field polarity Toward the solar wind) negative polarities.

observatory shows a statistically significant relation with the amplitudes of the solar and lunar variations of the EMF. All components of the EMF and $K$-index show an increase in amplitude generally with increasing sunspot number as $N_{m} F_{2}, f_{0} F_{2}$ and subpeak electron content (Agopyan and Bulat, 1990).

\section{Discussion of results and conclusions}

The results presented in the graphs may be summarized as follows:

a) The $F$-layer starts to rise up in a rather normal way near sunset. Coincident with this rising of the layer where there are sudden increases in ionization, which reaches a value about $60 \%$ to $70 \%$ larger than its normal level, for the three SSCs.

- SC1-(29 October 196811 h 09 LT, $K_{p}=7$ ), - SC2-(31 October $\left.196811 \mathrm{~h} 00 \mathrm{LT}, K_{p}^{p}=8\right)$ and - SC3-(1 November 196811 h 17 LT, $K_{p}=7$ ). b) For the 3 cases represented in figures, after reaching a maximum of concentration excess $\left(\Delta f_{0} F_{2}\right)$, the layer and $\Delta f_{0} F$ go down by about 100 $160 \mathrm{~km}$ and then return to normal.

c) The negative phase for the third storm is very marked and coincides with a possible $e x$ pansion of the $F$-layer.

Possible dominant mechanisms for the increase in ionization concentration about 8-10 h after the SSC could be:

i) intensification of the neutral wind circulation equatorward bringing up ionization to the regions of lower recombination processes;

ii) ionospheric feeding by plasma, flowing from the plasmasphere towards the equator due to its compression. This compression could be due to the $E \times B$ ions drifting from polar (higher) to equatorial (lower) $L$-shells causing further motion along magnetic flux tubes. The saturation of the flux tubes is reached after 8-10 h.

The reason for the rapid decrease following the peak of concentration could be due to:

i) a sudden change in the structure of the 
electric field that causes downward drift to the $F$-layer as a whole to regions of higher recombination processes;

ii) a sudden change in direction of the neutral winds.

The source of heating of the thermosphere at lower latitudes is more difficult to understand. It appears that the $F$-layers oscillate afterwards, as illustrated by its wavelike structure. The return to higher values of $F$-layer heights could be due to the following:

i) the sudden vanishing of the special structure of the electric field;

ii) the returning of neutral wind to normal conditions.

Nevertheless, the positive phase cannot be due to the increase of ionizing radiation from the Sun because in that case we would observe a positive peak rather closer to the SC of the storm. From the aeronomic point of view, in general, Istanbul $(L=1.6)$ experiences equatorial storm characteristics because of its location in the same longitudinal network as Athens $(L=1.4)$, Rome $(L=1.6)$ and Cape Kennedy $(L=1.8)$ and it also shows phase similarities, parallel morphologic features, and characteristic Mendillo Peak. For the geomagnetic latitude of Istanbul, with a plasmapause location value $L=1.6$ for $K_{p} \geq 7$, the saturation of the protonospheric reservoir would be expected to take $t_{s}=0.17(L)^{4} \cong 1.1$ days (Kamide and Richmond, 1986). Thus one day is insufficient for its replenishment.

The case is not similar for stations having similar coordinates but it is for equivalent $L$ values. If the $F_{2}$ layer was completely solarcontrolled, the LT contour maps of $f_{0} F_{2}$ would follow lines of geographic latitudes (Fox and McNamara, 1988). It should be kept in mind that when the Sun is fast, with a lead-time of about a quarter of an hour (i.e. the equation of time is positive), there is an extreme energy injection into the ionosphere by way of the magnetospheric plasma and vice versa for the high solar geomagnetic activity conditions. During the times with $-B_{z}$ solar wind, the magnetosphere energy transfer function derived by Perreault and Akasofu (Akasofu, 1981) is dominant near $180^{\circ}$ due to the term $\sin ^{4} v / 2$. Here $v$ is the polar angle of the IMF vector in the $y-z$ plane of the solarmagnetosphere coordinate system. It is known that $\varepsilon=v B^{2} I_{0} \sin ^{4} v / 2$ where $v$ is the velocity of the solar wind, $B$ is the magnitude of the IMF and $I_{0}=7$ Earth radii. The variation of the $\varepsilon$ function gives evidence that the energy transfer from the solar wind into the magnetosphere is higher during IMF $T$ pro sectors than during $A$ anti sectors. After a CME only the variation of the solar wind speed determines the mean energy input, but the increase during the anti $\rightarrow$ pro sector transition is steeper than the decrease during the transition from pro $\rightarrow$ anti sector. Plasma-sheet distance depends on cross-tail potential drop, $\Phi_{T}$, or cross-polar cap potential, $\Phi_{c p}$, and $\Phi_{T}$ in turn depends on $\varepsilon$ via the relation $\Phi_{T}^{c p} \cong \Phi_{p c} \propto \sqrt{\varepsilon}$ with the correlation coefficient $\propto 0.92$ where the power $(\varepsilon)$ of solar windmagnetosphere dynamo changes as a function of time (Reiff et al., 1977). The sources of temperature increases and their physical explanations give the most reliable information. But magnetic activity variations still remain a critical area needing improvement for all models (Hedin, 1988).

\section{Acknowledgements}

The Author wishes to thank Prof. Dr. Taner Bulat for his leading cooperation of ionogram scaling and Prof. Dr. Stuart R.C. Malin for his critical review of the manuscripts. I would also like to thank Professors Abdus Salam, Luciano Bertocchi, Giuseppe Furlan, Neille J. Skinner and Sandro M. Radicella, the International Atomic Energy Agency, UNESCO for hospitality at the ICTP, ICS, and ICEM. I am indebted also to Dr. Emin Demirbag and Mr. Taner Arslan for their computer assistance.

\section{REFERENCES}

AGOPYAN, H. (1986): Ionospheric behaviour on geomagnetic storms, in Proceedings of the International Symposium on «Radio Beacon Contribution to Study of Ionization and Dynamics of the Ionosphere and Corrections to Geodesy», Oulu, Finland, edited by ANTTI TAURAINEN, Part-1, 11-25.

AGOPYAN, H. (1988): Severe magnetic storm effects on the ionosphere over Istanbul, in Proceedings of Abstracts on «International Beacon Satellite Symposium (IBSS) 88 on the Investigation of the Ionosphere by Means of 
Beacon Satellite Measurement», April 18-21, Beijing, China, edited by CAO CHONG, China Research Institute of Radiowave Propagation, 2.

AGOPYAN, H. (1996): The reason for severe magnetic storm effects in the ionosphere over Istanbul (ST066), in XXI General Assembly of the European Geophysical Society, 6-10 May 1996, "Solar Terrestrial Events and Their Effects on the Ionosphere and Atmosphere (ST10)», The Hague, Holland, Ann. Geophysicae, suppl. III, vol. 14, C755.

AGOPYAN, H. and T. BULAT (1990): The Changes of Subpeak Electron Content of The Ionosphere Depending on Seasons and Sunspots, Pubblication of Istituto Nazionale di Geofisica n. 523, Roma, Italia.

AKASOFU, S. (1981): Energy coupling between solar wind and the magnetosphere, Space Sci. Rev., 28, 121-190.

AKASOFU, S. and S. CHAPMAN (1963): The development of the main phase of magnetic storms, J. Geophys. Res., 68, 125-129.

BREMER, J. (1988): The influence of the IMF structure on the ionospheric F-region, J. Atmos. Terr. Physics, 50, 831-838.

Bulat, T. and H. AgOPYAN (1980): Tepealti elektron yogunlugunun gunes lekelerine ve mevsimlere gore degisimi (The changes of sub-peak electron content of ionosphere depending on seasons and sunspots), in 7th Turkish Scientific and Technical Research Association Congress, Tubitak, Izmir, Turkey, 387-392.

Claerbout, J.F. (1985): Imaging the Earth's Interior (Blackwell, Oxford, England), 67-75.

DUNGEY, J.W. (1961), Interplanetary magnetic field and auroral zones, Phys. Rev. Lett., 6, 47-48.

FÖRSTER, M. and N. JAKOWSKI (2000): Geomagnetic storm effects on the topside ionosphere and plasmasphere: a compact tutorial and new results, Surv. Geophys., 21, 47-87.

Fox, M.W and L.F. MCNAMARA (1988): Improved worldwide maps of monthly median $f_{0} F_{2}$, J.Atmos. Terr. Physics, 50, 1072-1086.

HEDIN, A.E. (1988): Atomic oxygen modeling in the upper thermosphere, Planet. Space Sci., 36, 907-920.

Hewish, A. and P.J. DUfFET-SMITH (1987): A new method of forecasting geomagnetic activity and proton showers,
Planet. Space Sci., 35, 487-491.

ISSIKARA, A.M. (1971): The solar and lunar influences on the Earth's magnetic field at Istanbul, Revue de la Faculté des Sciences de 1'Universite d'Istanbul, Geophysique, Ser. C, 36, 117-127.

KAMIDE,Y. and A.D. RICHMOND (1986): Recent advances in studies of magnetosphere ionosphere coupling, J. Geomagn. Geoelectr., 38, 653-714.

Matsushita, S. (1959): A study of the morphology of ionospheric storms, J. Geophys. Res., 64, 305-321.

MC ILwAIN, C.E. (1961): Coordinates for mapping the distribution of magnetically trapped particles, J. Geophys. Res., 66, 3681-3691.

MENDILlO, M. and J.A. KLOBUCHAR (1975): Investigations of the ionospheric $F$-region using multistation TEC observations, J. Geophys. Res., 80, 643-650.

Press, W.H., B.P. FlanNery, S.A. TEUKOLSKY and W.T. WeTtERLING (1988): Numerical Recipes, The Art of Scientific Computing (Cambridge University Press), 420-429.

PRÖLSS, G.W. (1987): Storm induced changes in the thermosphere composition at middle latitudes, Planet. Space Sci., 35, 807-811.

REES, D., T.J. FulleR-Rowell and H. Risbeth (1988): The use of mass spectrometer measurements to derive thermospheric temperatures and density, Planet. Space Sci., 36, 281-290.

REIFF, P.H., T.W. HILL and J.L. BURCH (1977): Solar wind plasma injection at the dayside magnetospheric cusp, J. Geophys. Res., 82, 479-491.

Tsurutani, B.T., W.D. GonZALES, F. TANG, S.-I. AKASOFU and E.J. SMITH (1988): Origin of interplanetary southward magnetic fields responsible for major magnetic storms near solar maximum (1978-1979), J. Geophys. Res., 99, 8519-8531.

UYAR, M.O. (1964): Magnetic Storms, Republic of Turkey, Ministry of National Education, Magnetic Service of Kandilli Observatory Istanbul, 1-5.

(received April 8, 2002; accepted October 11, 2002) 